\title{
Meeting the Felt-Need of Married Couples: The Case of a Diocesan Family Planning Program
}

\author{
Noel G. Asiones ${ }^{1, *} \&$ Fides Flores-Carlos ${ }^{1}$ \\ ${ }^{1}$ Institute of Religion, University of Santo Tomas, Manila, Philippines \\ *Correspondence: Institute of Religion, University of Santo Tomas, Manila, Philippines. E-mail: \\ noelgasi2000@yahoo.com
}

Received: May 13, 2017

Accepted: June 8, 2017 Online Published: July 5, 2017

doi:10.5430/wjss.v4n2p32

URL: https://doi.org/10.5430/wjss.v4n2p32

\begin{abstract}
Drawing on the concept of program integrity, this paper assessed whether or not the Natural Family Planning program of a church organization met the felt-need for family planning of married couples as its intended clients. Program integrity is the practical concept that programs should be organizationally and structurally sound to meet the needs of their intended recipients. It includes the five key elements of fidelity, dosage, reception, quality of service and program differentiation. Multiple focus group discussions were conducted with the service providers and married couples to gather data on its objectives, processes and outcomes. Except for the element of fidelity to the program's explicit objectives and values, the data clearly and consistently suggest that, in the case under observation, the program did not adequately meet the felt-need of the married couples for family planning in terms of the four elements of dosage, reception, quality of service delivery and program differentiation. Related to the five elements of program integrity, implications to theory and pastoral practice were drawn and specific recommendations made to enhance processes and achieve desired outcomes.
\end{abstract}

Keywords: natural family planning, program integrity, unmet- need

\section{Introduction}

Unmet need for family planning (FP) refers to the "proportion of currently married women who are not using any method of FP but do not want any more children or prefer to space births (Casterline, Perez, Biddlecom, 1997). Eliminating or addressing the unmet need for FP is expected to result in a substantial decline in fertility, reduce rates of population growth and serve national population goals (Visaria, 1997). As a counterpart to the government's own FP program, the hierarchy of the Roman Catholic Church (RCC) in the Philippines, through its influential conference of bishops (Catholic Bishops' Conference of the Philippines, henceforth, CBCP), promotes natural family planning (NFP) methods as the only "acceptable solution" to high population growth in the country. Its Second Plenary Council of the Philippines teaches that "married couples must exercise responsible parenthood and towards this end must plan their families according to the moral norms taught by the Church" (CBCP, 1991). Moreover, it strongly disagrees with the government's view that the artificial methods of FP are the best way to address the high population growth and denounces them as anti-life that promotes a "culture of death."

However, there also appears to be a wide consensus among church' observers that, while it represents the most vocal opposition to the government's FP program, the church as an institution has not exerted sufficient and sustained efforts to promote, in its own words, "a broader, more decisive, and more systematic natural methods of regulating fertility that are known, respected, and applied" (CBCP, 1991). Francisco, to cite an example, pointed out that this may be because "the flow of power and communication from the "teaching church" to the "listening church" had not been effective and successful in convincing married couples to abide or at least agree with its directives and opposition against the artificial means of birth control (Francisco, 2013). Other studies also found that even church-going Catholics are influenced far more by popular culture and folk tradition rather than by Catholic teaching on sex and reproduction (Atun, 2013).

This could partly explain, based on the latest 2011 Family Health Survey (FHS), why unmet need remains consistently 
high at 19.3 percent, 10.5 percent for birth spacing, and 8.8 percent for limiting births. It also revealed that less than one percent $(.3 \%)$ of currently married women used modern NFP methods either for achieving and postponing pregnancy (Erikta, 2012). It is in view of what she believed as an incredibly low number of Catholic couples using the modern method of NFP that the late Sr. Pilar Verzosa, an NFP advocate, once suggested surveying the promotion of NFP in the parishes throughout the Philippines (Verzosa, 2012). In order to fill in the perceived gap in knowledge of the extent and manner NFP methods have met the needs of married couples, this study was conducted in the diocese of Novaliches.

To attain this main objective, the study conducted the following activities: (1) collect data on the dioceses' ANFP program in terms of the key elements of program integrity; (2) determine the reasons for the reception and rejection of the NFP methods; and (3) propose improvements in the key elements of program integrity. Program integrity is the practical concept that programs should be organizationally and structurally sound to meet the needs of their clients (Berkel, Schoenfelder, \& Sandler, 2011). A program can be said to have program integrity when it: (1) is driven by and adhere to its organization's mission or purpose (fidelity), (2) is able to provide adequate amount of service and goods to its clients (dosage), (3) is accepted and used by the clients as credible and viable alternative that can fit their own circumstances and preference (reception), assists them to meet and satisfy their needs, (4) delivers services in ways which please and empower them (quality of service delivery), and (5) is able to allow them to more appreciate its credibility and viability when compared with other services or products that are available in the market or program differentiation/adaptation (Duttweiler \& Dayton, (2009). They are widely recognized as predictors of program outcomes and impacts. For Berkel and her partners, fidelity, quality of service delivery and adaptation are behaviors of program facilitators, and reception or responsiveness to the program is the behavior of the intended recipients which in this case are the married couples (Berkel et al., 2011).

\section{Methodology}

\subsection{The Participants}

A total of 20 out of the 30 service providers belonging to the diocese (10 females, 10 males) participated in the three FGDs conducted for them who ranged in age from 40-70. Most of them were married for at least 20 years. Many are still working in the corporate or government sectors but a few are already retired, and almost all of them had at least a college education. Eight of them were members of the Couples for Christ (CFC) movement before they became involved in the ANFP program of the diocese.

A total of 60 married couples from 5 parishes (46 females, 14 males) participated in the eight FGDs conducted for them who ranged in age from 26 to 65 . The average number of years of their marriage was 20 and the average number of children was four. The females are mostly plain housewives while the males are overseas workers, seamen, factory workers, drivers, or vendors. They reported having used both NFP and artificial methods during the course of their marriage. All of them are Roman Catholics, many had at least a secondary education and most belong to low resource sector, somewhat representing a particular demographic segment of married couples in the diocese.

While the service providers were relatively very accessible, the married couples were "hidden" or "hard-to-reach" population partly because the diocese, much unlike the Prelature of Ipil, did not have yet a dataset of the past acceptors and users of the NFP methods (Research Institute for Mindanao Culture, 2006). This was also the reason why the researchers decided to drop the diocese of Cubao as one of the research sites, in spite of repeated and persistent efforts to establish rapport with its church leaders and service providers. To address this limitation, snowballing technique and the use of privilege access to interviewers and gatekeepers were employed. The researchers established rapport with those being research and with those accessing them on their behalf.

\subsection{Research Site}

The Roman Catholic Diocese of Novaliches is a diocese of the Catholic Church in the Philippines, with a Catholic population of 1.6 million (76.2\%). Its territorial jurisdiction includes the District 2, 5, and 6 as well as Old Balara Village in Quezon City, and 23 villages in North Caloocan City. The current head of diocese is Bishop Antonio Tobias (The Catholic Directory of the Philippines, 2014). 


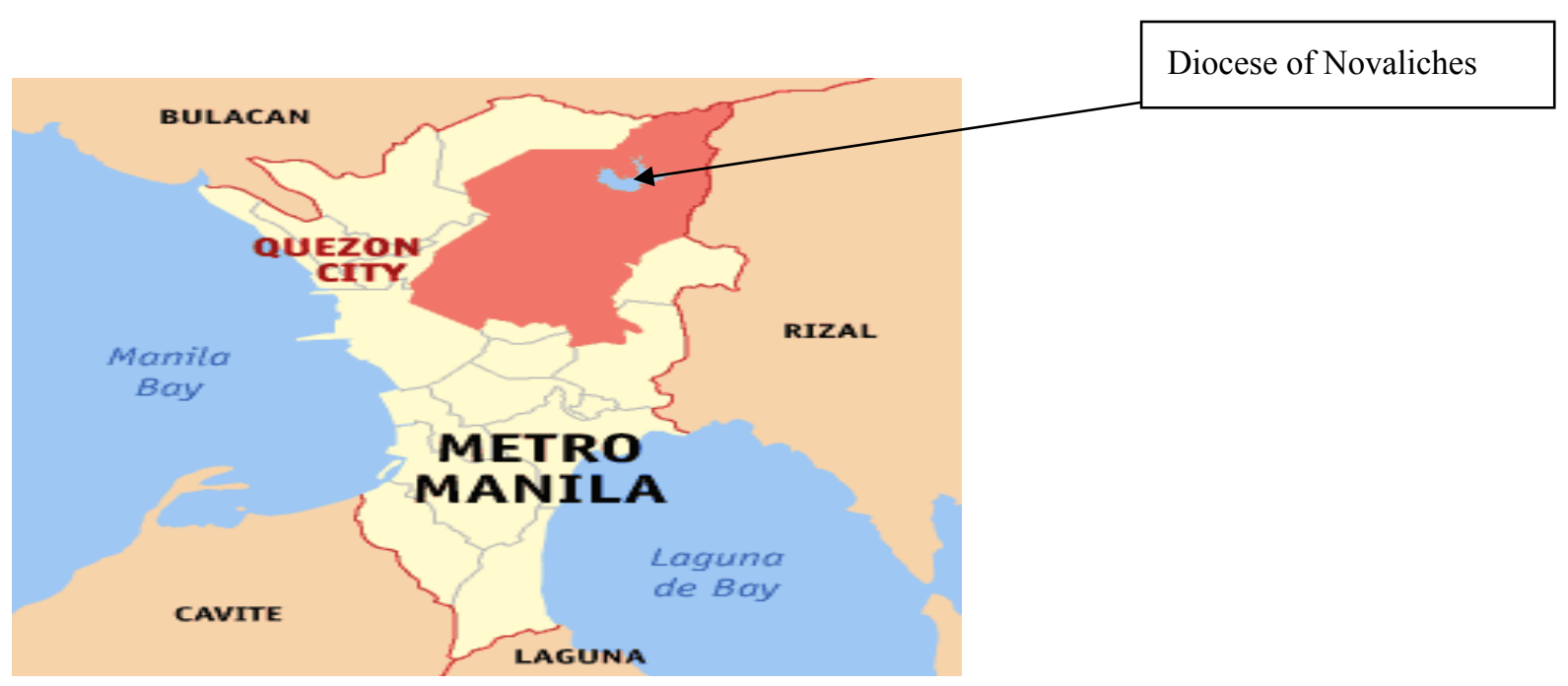

Figure 1. Map of the Diocese of Novaliches

\subsection{Instrument}

A lengthy and careful process was conducted to develop the focus group discussion guide. Although separate interview guides were created for the service providers and the married couples, a mix of open-ended "grand tour" and probing questions to mine participants' ideas, emotions, and orientations. The preliminary interview guides were pilot-tested with a service provider and a married couple. Based on the findings from the pilot interviews, the interview guides were revised. Probing questions were added to gather more detail on salient issues. The interview guides were fine-tuned during the interview period, between December 2015 and May 2016. Interview responses were strictly treated as confidential and, although a token of appreciation was provided by way of snacks and bottled water to most of the groups, compensation was not provided for their participation. All participants agreed to record the interviews during the FGDs which took an average of 40 minutes only. To ensure fidelity to their reported description of the program, participant validation was conducted for the service providers.

\subsection{Analysis of Data}

The scissor-and-sort technique was used to treat and analyze discussion data (Stewart, Shamdasani, \& Rook, 2007). After all the FGDs were completed, the following steps were taken: (1) transcription of collected data, (2) review of data, (3) identification of data that were relevant to the research questions, and (4) classification or coding of data according to the major topics and issues. The coded materials were sentences, phrases or long exchanges between the moderator and participants. Once the coding process was completed, the coded copy of the transcribed discussions was cut apart, sorted and placed together to provide the basis for developing the report. The various pieces of transcribed texts were used as supporting materials and incorporated within an interpretative analysis.

\section{Findings}

The service providers were all volunteers and had not received any form of compensatory salaries. According to the program head, there were only, when the FGDs were being conducted, 30 NFP service providers for the whole diocese. A great majority of them claimed to be acceptors and users of the NFP methods which they found effective in either achieving or postponing pregnancy and even in selecting the gender of their children. They maintained that practicing what they teach mostly during Pre-Cana Seminars (PCS), contributed to their commitment, competence, and credibility as NFP providers.

The CFC members recalled giving lectures on NFP in some remote parts of the country. Upon the invitations from the local government units of different provinces, they promoted modern NFP methods such as Basal Body Temperature (BBT), Sympto-Thermal Method (STM), Lactational Amenorrhea (LAM), and Billings Ovulation Method (BOM). The Standard Days Method (SDM) and Two-Day Method (TDM) were not included in their modules due to controversy and conflict with the BOM. Their trips to the provinces were funded by a non-governmental organization (NGO). They recalled that the program stopped in 2014 upon the passing of the 
Reproductive Health Law. However, there were times that some sectors (CFCs, villages, schools, parishes, offices, etc.) invited them to give instructions and training on fertility awareness.

One of them recalled that it was sometime in 2011 that the NFP Program was incorporated to the Family and Life Ministry (FLM) of the diocese, roughly ten years after it was created. Couples Demy and Sylvia clearly remembered that in 2014 they were invited to be coordinators for one of the diocese's vicariates. Demy eventually became the program head for the diocese in 2015. As service providers, the couples gave instructions on the four modern NFP methods. However, the SDM and TDM methods were taught by other teachers. In 2015, they reported that they conducted three training seminars for NFP counselors, two users' training for married couples, and conducted NFP talks in Buhay Pagmamahal (Love is life) and PCS organized by the diocese. In terms of needed facilities, they observed that there was no existing separate office for the NFP at the diocesan level until late last year (2015) when a full-time secretary was designated to coordinate the NFP-related activities of the diocese. The majority of the married participants in the FGDs said that they were not aware of the NFP program in their respective parishes.

\subsection{On Program Fidelity}

Program fidelity refers to the extent to which the program adhered to its explicit objective to meet the felt-need of married couples for FP. Coupled with the other key elements of program integrity, objectives that are clear and understood by the shareholders can contribute to their competence and commitment to the program (Vidal, 2001). They also direct action and attention to behaviors that the shareholders believe will more effectively attain it. Moreover, group members who accepted and understood their program objectives will most likely increase their efforts and commitment, and most likely will perform better than those who do not have clear and accepted goals (Weldon, Jen, \& Pradhan, 1991).

As one of the six programs of the FLM of the diocese, the service providers maintained that the explicit objective of the NFP was to promote family and life through the achieving and spacing of birth. According to Liza, one of the program coordinators, "The NFP program is the church's answer to the FP need of the married couples as taught by the encyclical Humanae Vitae." Lourdes, who is a registered nurse and a teacher in a nursing school, was more to the point. She said that NFP is for achieving and spacing birth not for limiting.

Unlike the artificial methods, they maintained that the NFP program is not a means to limit birth but to help married couples achieve or postpone pregnancy, space birth, and at times, to select the gender of the child. They insisted that it is wrong to use NFP in pursuit of contraception. Underlying this statement is the belief that, firmly in line with the official stance of the Catholic hierarchy, high population rate in the country is not the cause of widespread poverty but graft and corruption and unequal distribution of wealth. Thus, they expressed the belief that the solution does not lie in limiting birth or controlling population growth. This is clearly in line with the CBCP's own statement (Cruz, 2012).

They also maintained that it is also a way of life where values of respect for life as a gift from God are learned. In other words, they believe that the ANFP and artificial contraception do not have the same objectives. According to them, ANFP is non-procreative because it takes place during the infertile part of the woman's cycle. The artificial method is anti-procreative because it purposely thwarts fertility. The service providers maintained that the diocese promoted and provided instructions on all six modern methods for ANFP, namely, Billings Ovulation Method (BOM), Basal Body Temperature (BBT), Sympto-thermal Method (STM), Lactational Amenorrhea Method (LAM), Standard-Days Method (SDM) and Two-Days Method (TDM). Moreover, they insisted that they never promoted artificial methods as back-ups in the event that the former failed to work. Underlying this practice is the traditional teaching of the church that "natural family planning is the only morally acceptable way of practicing responsible procreation (CBCP, 1990).

\subsection{On Dosage}

Dosage refers to the frequency or amount of service (such as information campaign and counseling sessions) that the program delivered. As an element of program integrity, it influences the comprehension and competence of the married couples in their reception and use of NFP methods. Comprehension and competence influence their commitment to practice them in spite of their known associated requirements such as close monitoring of fertility cycles, correct and accurate information, and guidance, cooperation between the couples, periodic abstinence, and proper motivation in order to successfully use them.

Although a separate program for it at the diocese was reportedly in place, the service providers admitted that instructions and counseling on ANFP methods were for the most part given in the Pre-Cana Seminar (PCS). The PCS is a mandatory church program that provides would-be-couples, among others, of an overview of NFP methods. 
Jose, 62, a professional biologist, and an NFP trainer for the whole diocese, said in Filipino:

NFP is only inserted at the PCS and given an hour of lecture.

It was all introductions at the PCS. We tell them to use it,

and nothing more. There were no instructions on how to use them.

Perhaps the strongest articulation of the irrelevance of PCS at this stage of married life came from Jonadon, 47 years old with two children, who said:

We just wanted to have children at the start of our marriage.

This answer suggests the participants' perception that NFP methods may only be for limiting birth and not for conceiving or achieving pregnancy. The service providers also admitted that the harmful side-effects of the artificial methods of birth control are mentioned in the PCS. They also maintained that there were no follow-up sessions conducted due to, first, a lack of more competent, committed and credible trainers, and, second, insufficient funds. However, they recalled that there was once a plan to establish post-Cana seminars for married couples where a more detailed ANFP would have been taught. They also reported that it has been two years since they last gave a seminar on ANFP, noting that most of the attendees were women since the men were at work. Except for very few married couples who would make an appointment for face-to-face counseling on the NFP methods, there were hardly any activities conducted to promote at least fertility awareness among the married couples outside of the PCS.

This was later on echoed by the married couples in their FGDs. They said that one reason that they did not use NFP methods was because they were not as accessible as the artificial contraceptives that were being promoted and provided by the local government's health units in their neighborhoods. Thus, most of them admitted that they were forced to resort to using artificial methods such as pills, injectables, withdrawal, and ligation. Cresencia, 36, and Carmen, 32, said in Filipino,

We would have used NFP methods if we only knew about them.

\subsection{On the Quality of Service Delivery}

The quality of service delivery refers to the manner in which services and products are provided in a way that satisfies the customers or clients. A program with high quality of service delivery will satisfy the needs of its customers whilst remain competitive. Improve service quality may increase competitiveness as well as the trust and loyalty of the clients. Customer care assures the delivery of high-quality service. The principle of quality service is constantly examined to meet what customers expect, as opposed to merely meeting specifications. The customers may assess the quality of services according to two criteria: firstly, whether services assist them to achieve the outcomes that they expect, and secondly, whether services are delivered in ways which enable them to use the product (Crous, 2012). Recognizing the importance of their judgments of service delivery, Crous argued that for services to meet their needs and aspirations, customers themselves must be involved in improving them (Crous: 397). Evaluations must be based on customer expectations if they aim to become institutions that are truly responsive to their needs.

In terms of the first criteria, the service providers suggested that the NFP services being provided to married couples did not adequately meet the needs of married couples for FP. "It is all introduction, no follow-ups were done," as Jose said. He added that the bishop or priest will say,

Use NFP, but that is all. That is why NFP does not have an effect on people.

They also maintained that the PCS was not enough to meet the needs of married couples to plan their families. This was corroborated by many of the married couples. They said that at the start of their marriage, newly-weds had little interest in family planning and only wanted to have children. As Andrei typically put it,

The need for FP comes only after couples have at least two children and

when they are already getting older.

In terms of the second criteria, they also expressed the felt-need to be more empowered to deliver quality service to the married couples. Jose explains:

The volunteers are also employed. At times, we spend our own money.

The lack of trainers and volunteers has prevented a wider and broader information campaigns to married couples especially at the grass root levels. Insufficient financial support from the "higher ups" sometimes made them spend their own money for transport fares, snacks, and materials. 


\subsection{Reception of the NFP Program}

This domain mainly refers to the voluntary acceptance of the services offered by the program as useful and viable FP methods. Non-reception would indicate that the services being offered are not useful or viable.

The service providers maintained that they accepted, used and found the NFP methods viable and effective in planning their own families. They also expressed the strong desire to conduct information campaigns on them outside of the PCS. According to them, there were in the past few but failed attempts to make NFP more known and accessible to women of reproductive age. Sylvia said:

The married couples prefer to use NFP if they know how to use them.

However, they were not really taught outside of the PCS.

She also wondered about those who were not married in the church and who told her that, had they known about NFP methods, they would have most likely at least tried to use them. However, they also maintained that insufficient human and financial resources hampered, if not prevented them, from carrying out wider information campaigns. To explain this point, Sylvia recounts:

There was a time when we organized an NFP seminar;

we also prepared food and drinks.

However, only three women came because it was scheduled at the time

when a highly popular afternoon local show was held.

The service providers felt how tough it is to promote NFP methods especially if promoted only by them and not by the parish priest. The credibility of the NFP methods, or its reputation, as well the reputation of its service providers, had a significant effect on its reception by the married couples. It has the most direct impact on the couples' willingness and availability to attend seminars. Judging from the narrations of the service providers, it appears that the program did not enjoy a good reception and credibility with the married couples, especially among the husbands, whose more urgent priority is earning a living for their family. Carmen, a service provider, lamented:

It is not that easy to organize them, they do not have time.

The women are easier to invite, but with the men, it is almost impossible or

wishful thinking to have them cooperate.

The males' attitude towards the invitations to attend NFP-related meetings speaks volumes on how much they care about the issue of family planning. Lundgren and his associates noted that including male partners and encouraging their participation in counseling sessions may help couples overcome potential difficulties (Lundgren, Sinai, Arévalo, \& Jennings, 2006). Although they do not reject them in themselves, the service providers noted that the weak reception by the couples may be partly explained by the perception that the NFP methods do not produce immediate and tangible results like the artificial methods.

The service providers admitted that their own perceived lack of credible influence with the married couples may also explain poor reception of NFP methods. They repeatedly suggested that parish priests need to take the initiative in inviting married couples to attend NFP seminars. Based on their experience, they said that married couples tend to at least express intent to attend when it is the parish priest who would do the promotion.

On the other hand, the married couples maintained that (a) they were not duly informed about NFP by local government units in their village. Although they are open to and know that NFP methods are safe and would use them when given the opportunity, the married couples said that personal circumstances made them resort and used artificial contraceptives like pills, injectables, and ligation. Like her fellow housewives, Bella, whose husband is a construction worker, may be described as a hesitant acceptor and user of NFP methods:

In using contraceptives, we do not have to attend seminars, count, observe calendar, test our mucus.

She recalls that her husband once told her in Filipino:

I worked for six days at the construction site; six days a week

I am out of the house, if you do not sleep with me,

I will not give your share of my earnings. 
In its Pastoral Letter, Love is Life, the bishops pretty much said the same thing: "They did not receive adequate support from their priests. We did not give them due attention, believing this ministry consisted merely of imparting a technique best left to married couples" (CBCP, 1990). Atun asserted that" the Church may need to reconsider its position on modern family planning and instead of directing efforts to campaigns against artificial contraceptives through political means; it might be more helpful if the Church's efforts can be directed towards informing and instructing people about NFP methods (Atun: 234). In turn, she suggested that many forms of NFP such as standard-days method (SDM) and billings can be used successfully to space or limit births, but most NFP methods require close monitoring of fertility cycles.

\subsection{Program Differentiation}

This element refers to the married couples' assessment of the usefulness and viability of the NFP methods in order to ascertain their unique contributions to the desired outcomes when compared and contrasted with its competitor.

Almost all of the service providers who accepted and used the NFP methods reported that they found them viable and effective in achieving and postponing pregnancy, spacing birth and selecting the gender of their children. They also maintained that the NFP methods contributed to a better and improved relation with their partners. This is partly explained by the fact that majority of the service providers were well-educated and gainfully employed. The unmet need also decreases with increasing education; it is highest for currently married women with no education at all (29.2 percent) and lowest for those with college or higher education (17.6 percent) (Erikta, 2011).

This seems to be not the case with the married couples. The women who used artificial methods such as ligations, pills, injectables, and withdrawal found them relatively effective in spite of experienced harmful side-effects to their health. They also reported that the artificial methods were more accessible and provided without costs at the local health center. However, when asked which method they would prefer to use, they maintained that they would still prefer NFP methods because they are free and do not cause side-effects like a migraine, nausea, loss or gaining weight, cancer, and death. They said that NFP methods are not viable especially when their husbands would not cooperate or wait for their infertile periods. This is partly explained by the fact that majority of them are in poor households and of lesser educational attainment than the service providers. The total unmet need for FP is substantially greater among women considered poor $(25.8 \%)$ compared to non-poor women $(16.6 \%)$. In particular, 13.1 percent of poor women as compared to 9.4 percent of non-poor women have an unmet need for spacing, and 12.6 percent of poor women as compared to $7.2 \%$ of non-poor women have an unmet need for limiting.

The few women who used and found NFP methods viable expressed satisfaction and gratitude for not suffering from the side-effects of using artificial methods. Instead, they said that NFP made them feel the care and respect from their husbands who made some sacrifice by not making or letting them used artificial methods. In describing the positive effects of NFP on their conjugal relations, Carmen explains that "my husband's decision not to make me use artificial methods not only saved me from their harmful side effects but also made me feel important and loved by my husband." As Vande Vusse observed, "Among the positive effects of NFP on marital dynamics are relationship enhancements, knowledge improvements, spirituality enrichments, and method successes (Vande Vusse, Hanson, Fehring, Newman, \& Fox, 2009). They also found that majority of the couples reported that the NFP is beneficial, often resulting in stronger bonds, better communication, and improved knowledge between them.

\section{Discussion}

\subsection{Summary and Limitations}

This article provides qualitative data about the program integrity of a diocese's NFP program. Its capacity to secure resources, receive stable support from those holding leadership and managerial responsibilities, deliver quality and sustained services, all prove to be important contributing factors in achieving the objectives of NFP. Evidence show that the program was not implemented enough to complement CBCP's widespread promotion of NFP methods and uncompromising opposition to the artificial methods to reduce birth. Although the service providers clearly adhered to its underlying values and explicit goals, all the relevant evidence show that the FP program of the diocese yielded little in terms of the four key elements of dosage, quality of service delivery, reception and program difference. There is a consistency of findings from both groups regarding this observation.

First, the dosage was for the most part limited to the Pre-Cana Seminars (PCS). Given that they require comprehension, commitment, and skill to be viable, the reception and practice of NFP methods will hinge on the amount and quality of information, instructional and motivational campaigns provided to the clients by the service providers. One study found that when presented with an accurate description of church' teaching on FP many 
Catholic women show reluctance to completely reject its teachings (As cited in Moynihan, 2012). More importantly, the finding on the element of dosage confirms what previous studies already found in the past: that much work needs to be done to more broadly promote effective pastoral information and guidance on NFP methods. The lack of capacity to secure resources partly explains the program's inability to promote the broad and adequate amount of services and goods to the married couples. The lack of commitment from some church leaders, particularly, at the parish level also hampered, if not undermined, the capacity of service providers to do a better job in promoting ANFP to the married couples outside of the PCS.

Second, the low quality of service delivery also partly explains the inadequate dosage of information and instructions given to the married couples. Although a Commission on Family and Life was in place at the parish level, it appears that there was no coordinating office to deliver NFP-related services to the married couples, especially at the grass root level. As a result, its services were largely confined to the church-mandated PCS. Moreover, the continuity and sustainability of the services pretty much depended on the discretion of the current parish priest. This has undermined its long-term quality of service delivery in a number of ways. It had a demoralizing effect on the service providers since it gave them the impression that the program was only something "personal" rather than the result of a conscious and focused the mission-driven process of the organization (Gomez, 2006). It also prevented the program from building and maintaining the momentum that can enable the service providers to gain self-confidence as well as credibility among the married couples who over time had begun to grow tired and impatient with its perceived lack of immediate and tangible outcomes. And it appears to be losing the market competition against its counterpart's broader, more decisive, more organized and systematic efforts to promote artificial methods (Seltzer, 2002). Many of the married couples have used the artificial methods not so much because of conviction but because, unlike the NFP methods, they were more accessible and less difficult to use (Trussel et al., 2012).

As a result, reception of the program proved to be difficult for the married couples. Although the married couples said that they would prefer to use the NFP methods had they known them before, they were forced by their circumstances to resort to the more accessible and familiar artificial methods. The few who initially accepted and practiced the NFP methods found them difficult because they required the disciplined cooperation of both couples. The husbands usually failed in this regard. More importantly, and as FHS studies consistently showed, the economic context of the married couples played a significant influence on what methods they would use (Erikta, 2012). Those belonging to the low sector and with less education tend to use artificial methods because NFP suffers from the persistent perception that it is unreliable, unacceptable and ineffective and lack of information and training on how to use NFP methods. Thus when asked what they would prefer to use, not very few said that they will use artificial methods.

In interpreting these findings, two limitations of the study must be kept in mind. One is the limited number of participant-married couples, particularly the males/husbands, from the other 58 parishes of the diocese. The other is that those who hold leadership and managerial positions in the diocese were not included in the study. A complete picture of the program would have been taken had they been given the opportunity to participate and be heard in the FGDs.

\subsection{Implications}

In general, the integrity of the diocesan NFP program was not sound enough to implement and achieve a "broader, more decisive, and more systematic natural methods of regulating fertility that is known, respected and applied" by the Catholic married couples charged to its pastoral care. Specifically, first, the program lacks the capacity to secure adequate resources to meet the felt-need of married couples for family planning outside of the church-mandated Pre-Cana seminars. Second, the program lacks the capacity to develop a strong internal management and governance system that can allow the service providers greater control in its implementation. Third, the program lacks the capacity to deliver quality and sustained the amount of NFP-related programs and services especially to married couples with lesser education in poor neighborhoods. Orbeta found that the larger number of children among poorer families can be more attributed to poor practice than the desire for more children (Orbeta, 2003). And finally, the service providers lack the concentrated attention and support that they badly needed and deserved in order for them to implement a broader, more decisive and more systematic natural family planning methods in and for the diocese.

The findings from this study raise several questions that would be valuable avenues of future research for scholars. First, to what extent does socio-economic characteristics of married couples relate with their felt-need for FP? To the extent that there is an evident variation in the reception and practice of NFP methods, is it because of difference in economic status, educational attainment, or do other factors come into play? (David \& Atun, 2004).

Further attention should also be paid to the influence of those who hold leadership and managerial position in the 
diocese on the program's quality of service delivery. By and large, the study has shown that the lack of support and assistance from church leaders undermined the program's stability and sustainability across time. Will the program be more effective when its control and implementation be given fully to the service providers?

Finally, more needs to be done to explore how the husbands can be made more open and cooperative in the reception and practice of the NFP methods. Perez argued that one essential aspect of NFP is how to motivate couples to abstain from sexual intercourse during the woman's fertile period (Perez, 2009). What can be done to enable them to be motivated and become more competent in the use or practice of the said method in the context within which they find it difficult, if not impossible, to cooperate with their partners? Studying the effects of the influence of economic status and source of livelihood will further enhance the understanding of the psycho-social conditions under which they operate.

\section{Conclusion}

There is much to be done in order to meet the felt-need of married couples by the church organization under study. It needs to improve its organizational capacities in order to achieve the desired outcomes and impacts for the married couples charged to its care. In particular, significantly improving on its ability to secure resources, both human and financial, may well very be the fuel that will make the difference between what it wants to achieve and what it can do. It is indeed unfortunate that the lack or absence of program integrity compels the married couples, particularly those who are living in marginalized and depressed areas, to resort to the more accessible artificial methods of family planning. The church organization may no longer tarry and wait for the married couples to lose whatever credibility the natural family planning program has for them. The time is right now.

\section{Acknowledgements}

We wish to thank sincerely a number of organizations and peoples who helped the researchers in this challenging but exciting research endeavor. There are certainly few things in life that one can do alone; doing research is certainly not one of these. Since day one of this one-year journey, my research partner and I have to depend on both friends and perfect strangers to keep us going. With grateful hearts, we acknowledge the following: Dr. Clarence Batan, Research Director of the Research Cluster for Cultural, Educational and Social Issues of the University of Santo Tomas, Manila, Archbishop Antonio Ledesma, S.J., Professor Pablito Baybado, the husbands and wives of the Couples for Christ of the Novaliches Diocese, especially Engineer Demy and Sylvia Sanchez, Rev. Father Aristeo de Leon, and last but not the least, the married couples who readily and enthusiastically made themselves available for the focus group interviews amidst their busy schedules and commitments.

\section{References}

Atun, J.M.L. (2013). Religiosity and Contraceptive Use among Filipino Youth. Philippine Center for Population and Development. Retrieved from http://www.pcpd.ph/.../religiosity-and-contraceptive-use-

Berkel, M., Schoenfelder, E., \& Sandler, I. (2013). Putting the Pieces Together: An Integrated Model of Program Implementation Prevention. Science, 23. http://dx.doi.org/10.1007/s11121-010-0186-1

Casterline, J.B., AE Perez \& AE Biddlecom. (1997). Factors Affecting Unmet Need for FP in the Philippines. Studies in Family Planning, 3, 173-191.

Catholic Bishops' Conference of the Philippines. (2011 a). Guiding Principles of Population Control. Retrieved from www.cbcponline.net/

(1993 b). In the State of Mission: Towards a Renewed Integral Evangelization: National Pastoral Plan, b: 32 .

. The Second Plenary Council of the Philippines, (1991, c). Retrieved from www.cbcponline.net/

. Love is Life: A Pastoral Letter on the Population Control Activities of the Philippine Government and Planned Parenthood Association (1990, d). Retrieved from cbcponline.net/v2/?p=324

Crous, M. (2006). Quality service delivery through customer satisfaction. Journal of Public Administration, 397-398.

Cruz, O. (2012 August 06). CBCP insists "Contraception is Corruption" before House votes on RH Bill. Philippine Daily Inquirer, p. B1. 
David, C., \& Atun, JM. (2014). Factors Affecting Fertility Desires in the Philippines. Social Science: Diliman: 100. 2014. Retrieved from jounals.upd.edu.ph/index.php/socialsciencediliman/article/viewFile/4407/3999

Duttweiler, M., \& Dayton, S.F. (1993). Program Integrity: A Powerful Organizing Construct of Just More Jargon? Journal of Extension, 5(47). Retrieved June 25, 2015 from www.joe.org/joe/2009october/comm1.php

Erikta, C. (2012). Unmet Need for Family Planning Remains High: Results from the 2011 Family Health Survey. Retrieved from http://www.census.gov.ph/tags/family-health-survey.

Francisco, J.M. (2013). Letting the Texts of RH Speak for themselves: (Dis) continuity and Counter Point in CBCP Statements. Philippine Studies: Historical and Ethnographic Viewpoints, 223. Retrieved from www.philippinestudies.net.

Gomez, F.B., O.P. (1996). The Role of Priests in Natural Family Planning. Boletin Ecclesiastico de Filipinas, LXXII, 163.

Lundgren, R., Sinai, I., Arévalo, M., \& Jennings, V. (2006). Fertility Awareness-Based Methods of Family Planning: Predictors of Correct Use. International Family Planning Perspective, 94-95.

Moynihan, C. (2012). What Catholic Women Think about Faith, Conscience and Contraception. Retrieved from http://: www.catholiceducation.org/.../what-catholic-women-think-about-faith-conscience-an

Orbeta, A., Jr. (2006). Poverty, Fertility Preferences, and Family Planning Practice in the Philippines. Philippine Journal of Development, 129. Retrieved from https://ideas.repec.org/p/phd/dpaper/dp_2005-22.html

Perez, A. (1998). General Overview of NFP. Genus, 75. Retrieved from www.jstor.org/stable/29788564

Seltzer, J.R. (2002). The Origins and Evolution of Family Planning in Developing Countries. Published by RAND Corporation. Retrieved from http://www.jstor.org/stable/10.7249/mr1276wfhf-d

Stewart, D., Shamdasani, P., \& Rook, D. (2006). Analyzing Focus Group Data. Retrieved from www.sagepub.com/upm-data/11007_Chapter_7.pdf

The Research Institute for Mindanao Culture. (2006). Meeting the Felt Needs of the Couples in the Ipil Prelature of Zamboanga, Sibugay: An Assessment of the All-NFP Program. Retrieved from www.pcpd.ph/uploads/.../e2785a6b8a95c6eded5a7cea03f510b7.pdf

Trussel, J., Jewell, A., Billings, J.J., Howitt, M.B., Hume, K., Jarvis, G, Coleen, N., Odeblad, E., \& Piper, C. (2008). Reproductive Health Matters, 2, 63-67.

Vande V., Hanson, L., Fehring, R., Newman, A., \& Fox, J. (2003). Couples' Views on the Effects of Natural Family Planning on Marital Dynamics. Journal of Nursing Scholarship, 35(2), 171-172. https://doi.org/10.1111/j.1547-5069.2003.00171.x

Verzosa, P. (2010). Do you agree? Effective NFP Program is the answer to counteract the RH Bill. Lovelife. Retrieved from www.cbcponline.net/

Vidal, A.C. (2001). Faith-based organizations in Community Development. Retrieved from www.huduser.org/publications/pdf/faith-based.pdf.

Visaria, L, (2008). Unmet need for FP in Gujarat. Economic and Political Weekly, 29. Retrieved from http://www.jstor.org/stable/4405341.

Weldon, E., Jenh, K., \& Pradhan, P. (1991). Processes that mediate the relationship between a group goal and improved group performance. Journal of Personality and Social Psychology, 61(4), 555-56. https://doi.org/10.1037/0022-3514.61.4.555 